\title{
Comparison of Insulin, Sulfonylurea and Sulfonylureas-Metformin Combination on HbA1c and eGFR Level on Age-, Sex- and BMI-Matched Groups of Indonesian Type 2 DM Patients
}

\author{
Sylvia Sylvia, Rani Sauriasari*, Retnosari Andrajati \\ Faculty of Pharmacy, Universitas Indonesia, Depok, INDONESIA.
}

\begin{abstract}
Objective: This study aimed to evaluate efficacy of insulin, sulfonylurea, and sulfonylureas-metformin combination in reducing the $\mathrm{HbA} 1 \mathrm{c}$ level and preventing renal function decline in type 2 diabetes mellitus (DM) patients in Indonesia. Methods: A cross-sectional study was conducted at Dr. Sitanala Hospital involving 105 patients who were taking: insulin (30), sulfonylureas (30) and sulfonylureas-metformin combination (45). The subjects were classified into age-, sex- and BMI-matched groups. We measured their $\mathrm{HbA} 1 \mathrm{c}$ level and serum creatinine to calculate eGFR level. Results: There were no differences among the three groups in term of age, sex, BMI, occupation and exercise habit. However, diet and family history of DM were different between the three groups. The average of $\mathrm{HbA} 1 \mathrm{c}$ levels in the sulfonylureas-metformin group was $7.46 \pm 1.81$ and showed a significant difference compared to the insulin group $(8.27 \pm 1.74)$ with $p=0.042$. No significant difference existed in eGFR in the three groups $(p=0.476)$. Subjects with obesity or BMI $>30 \mathrm{~kg} / \mathrm{m}^{2}$ had 3.268 times probability $(p=0.001)$ of having $\mathrm{HbA} 1 \mathrm{c}>7$ relative to underweight $(\mathrm{BMI}<18.5 \mathrm{~kg} /$ $\mathrm{m}^{2}$ ), after adjustment for comorbidity, diet and exercise habit. Subjects
\end{abstract}

with diabetic family history had 1.616 times relative risk to have $\mathrm{HbA} 1 \mathrm{c}$ level $>7 \%$, compared to those without diabetic family history $(p=0.002)$. Conclusion: We found in this study site that sulfonylureas-metformin combination was more efficient in decreasing HbA1c level in type 2 DM patients compared to insulin or sulfonylureas monotherapy. Family history of DM and overweight had considerable effect on uncontrolled HbA1c. Meanwhile, there was no significant difference among the three groups in preventing the decline of eGFR.

Key words: Diabetes Mellitus, HbA1c, Insulin, Sulfonylureas, Metformin. Correspondence

Dr. Rani Sauriasari, Faculty of Pharmacy, Universitas Indonesia, Depok, INDONESIA.

Phone: +62-821-14252811

Email: rani@farmasi.ui.ac.id

DOI: 10.5530/jyp.2018.10.102

\section{INTRODUCTION}

The prevalence of type 2 diabetes mellitus (DM) worldwide is expected to reach $44 \%$ in 2030 , which is about 366 million people. ${ }^{1}$ The total number of patients with DM in Indonesia shows a considerable increase from year to year. Year 2011 revision of Type 2 DM Consensus issued by PERKENI (Indonesian Society of Endocrinology) states that the prevalence of DM in Jakarta (urban area) in 1982 was 1.7\%, increasing to 5.7\% in 1993 and to $12.8 \%$ in $2001 .^{2}$ The prevalence of type $2 \mathrm{DM}$ in Indonesia in 2013 was $5.6 \%$ of the population and is projected to increase to $6.7 \%$ in 2035. ${ }^{3}$ Metformin and the second generation sulfonylureas (glibenclamide, glimepiride, gliclazide, gliquidone) are the longest oral antidiabetic medication used and are also the first choice for type 2 DM treatment. ${ }^{4,5}$ The Global Guideline for Type 2 Diabetes issued by the International Diabetes Federation-Clinical Guidelines Task Force in 2012 states that treatment of diabetes starts with metformin if there is no evidence of renal impairment or other contraindications. Sulfonylurea or alpha-glucosidase inhibitor can be used as initial therapy if there is contraindication to metformin. Insulin therapy is recommended for patients with type $2 \mathrm{DM}$ with initial HbAlc levels of more than $9 \%$ or if the blood glucose cannot be controlled with oral antidiabetic treatments. ${ }^{6}$ Diabetic nephropathy is one of the diabetes complications that has the highest incidence rate and often occurs during or shortly after the diagnosis is established. Approximately 3\% of patients had nephropathy at the time their type 2 DM's were diagnosed and in patients who have suffered for 10-20 years. In America, the total incidence of nephropathy is $3 \%$ per year. ${ }^{7}$ A cohort study conducted by Penno et al. has shown that fluctuation of the HbAlc level is associated with nephropathy. ${ }^{8}$ Previous studies on the effectiveness of oral antidiabetic drugs and insulin showed different results. A randomized controlled trial conducted by UKPDS in 1977-1997 on 4075 newly diagnosed type 2 DM patients showed that monotherapy with insulin, sulfonylureas and metformin increased the ratio of patients who can achieve HbAlc values below 7\% 2-3 times higher compared to the patients with diet alone. ${ }^{9}$ However, combination therapy of metformin with a sulfonylurea significantly increased the relative risk (RR) of cardiovascular disease or death (fatal and non-fatal incidence) compared to diet only, metformin monotherapy or sulfonylurea monotherapy..$^{10}$ Monotherapy with metformin only or in combination with sulfonylurea was associated with a reduction in all-cause mortality or cardiovascular disease compared to sulfonylurea monotherapy among new users of these drugs. ${ }^{11}$ Patients using sulfonylurea had an increased risk of initial eGFR persistent decline and the risk of secondary event ESRD (end state of renal disease) or higher mortality compared to patients taking metformin. ${ }^{12}$ With these varying conclusions, more researches still need to be performed.

Dr. Sitanala Hospital is a specialized hospital for leprosy that already opened for any other diseases and complete general hospital facilities are already available including specialist physicians. The list of top 10 prevalence diseases in 2014 from Outpatient Ward of Dr. Sitanala Hospital shows that from a total of 13,268 visits, type 2 DM ranks

This is an open access article distributed under the terms of the Creative Commons Attribution-NonCommercial-ShareAlike 4.0 License, which allows others to remix, tweak and build upon the work non-commercially, as long as the author is credited and the new creations are licensed under the identical terms. 
second with 1,894 numbers of visits (14\%). The total population of type 2 DM patients in 2014 were 223 patients. Treatments for type 2 DM in this hospital included sulfonylurea, the combination of sulfonylureametformin, insulin and oral antidiabetic combination, or merely insulin. Therefore, this study aimed to know whether sulfonylurea, the combination of sulfonylurea-metformin and insulin have different effects in reducing $\mathrm{HbAlc}$ and preventing the renal function decline.

\section{MATERIALS AND METHODS}

\section{Study Design, Study Population and Data Collection}

This study was conducted in cross-sectional study design. This study has been registered at the Ethics Committee, Faculty of Medicine, Universitas Indonesia-Dr. Cipto Mangunkusumo Hospital (No.76/UN2. F1/ETIK/2015) and at the Ethics Committee of Dr. Sitanala Hospital (No. DM.04.05/1/01662/ 2015). Informed consents were obtained from all individual participants included in the study. Subjects were defined as those who had been exposed to observed drugs for at least four months. Blood samples were taken from the subjects and were examined in a single accredited laboratory for HbAlc and serum creatinine. All of the samples were taken from type $2 \mathrm{DM}$ patients who came to the outpatient installation ward at Dr. Sitanala Hospital, Tangerang, during the study in February 2015 to May 2015. They were classified into three groups and consisted of 105 subjects, group 1 (patients taking insulin injections), group 2 (patients taking sulfonylurea monotherapy), group 3 (patients taking the combination of sulfonylurea-metformin). The inclusion criteria for this study were patients who had been diagnosed with type 2 DM for less than ten years, patients whose age were 30-70 years old and patients with original ethnics of Indonesia. The exclusion criteria were patients who were receiving the prescription of anti-infective drugs, supplements or vitamins and patients with leprosy.

Blood samples of the subjects were taken by a phlebotomist and assessed in a private clinical laboratory to get $\mathrm{HbAlc}$ and eGFR values. Body Mass Indexes (BMI) were calculated by the height and weight of every subject. Underweight was defined as having a BMI $<18.5 \mathrm{~kg} / \mathrm{m}^{2}$, normal as a BMI between $18.5-24.9 \mathrm{~kg} / \mathrm{m}^{2}$, overweight as a BMI between $25-29.5 \mathrm{~kg} / \mathrm{m}^{2}$ and obese as a BMI of more than $30 \mathrm{~kg} / \mathrm{m}^{2}$. Patients were interviewed to obtain data on their occupation, education level, diet, exercise, comorbidity and their family history of diabetes. Venous blood samples were collected by a certified phlebotomist and were transferred to vacutainer serum tubes. Then the samples were incubated at room temperature for $1530 \mathrm{~min}$ and centrifuged at $1000-2000 \mathrm{rpm}$ for $10 \mathrm{~min}$ in a refrigerated centrifuge. HbAlc and serum creatinine levels from the blood samples were analyzed by an accredited laboratory (Prodia, Tangerang, Indonesia).

\section{Calculation of eGFR}

Calculation of eGFR was conducted by using a formula derived by the Chronic Kidnev Disease Evidemiologv Collaboration (CKD-EPI).

$\mathrm{eGFR}=144 \times \frac{s \mathrm{Cr}(-0.309)}{0,7} \times 0.993^{\text {(age })}$

Equation for woman with $\mathrm{sCr}>0.7 \mathrm{mg} / \mathrm{dL}$ :

$\mathrm{eGFR}=144 \times \frac{s C r(-1.209)}{0,7} \times 0.993^{\text {(age })}$

Equation for man with $\mathrm{sCr} \leq 0.9 \mathrm{mg} / \mathrm{dL}$ :

$\mathrm{eGFR}=141 \times \frac{s C r(-0.411)}{0.9} \times 0.993^{\text {(age })}$

Equation for man with $\mathrm{sCr}>0,9 \mathrm{mg} / \mathrm{dL}$ :

$\mathrm{eGFR}=144 \times \frac{s C r(-1.209)}{0.9} \times 0.993^{\text {(age })}$
The Chronic Kidney Disease Epidemiology Collaboration (CKD-EPI) Equation is as follows:

\section{Statistical Analysis}

Data with a normal distribution were analyzed using one way ANOVA, whereas non-normal distribution data used Kruskal Wallis test. Chi-square test was conducted for categorical variables. We also performed logistic regression analysis with enter method. The results were considered significant if $p<0.05$.

\section{RESULTS}

The sampling flow of this study is described as a chart in Figure 1. From the medical records and the data from the pharmacy installation at Dr. Sitanala Hospital, we obtained the total number of patients with DM at 223 patients. A total of 105 patients met the inclusion and exclusion criteria and visited the outpatient ward during the sampling period. There were 30 subjects for the first group, 30 subjects for the second group and 45 for the third group.

\section{Characteristic Data of the Subjects}

Descriptive characteristics of the study subjects are shown in Table 1. There are no differences among the three groups in term of age, gender, BMI, occupation, exercise habit and comorbidity complications. However, diet and family history of DM are different between the three groups. The mean age of the patients is $54.98 \pm 7.47$, with women being more dominant $(71.15 \%)$. Subjects tend to be overweight where mean body mass index is $25.47 \pm 4.77$. Most of the study subjects have hypertension. Mean systole blood pressure of the subjects is over the normal range which was $149.89 \pm 25.92$ for the insulin group, $138.40 \pm 27.36$ for the sulfonylurea group and $129.81 \pm 16.21$ for the sulfonylurea-metformin combination group, although the diastoles are still in the normal range. This phenomenon is described in some literatures that many of Type 2 DM patients would have hypertension as well. ${ }^{13}$ Fasting plasma glucose and 2-h post-prandial plasma glucose in the Table 1 also meet the criteria of DM on Standards of Medical Care in Diabetes-2013 issued by the American Diabetes Association. This standard mentions that the

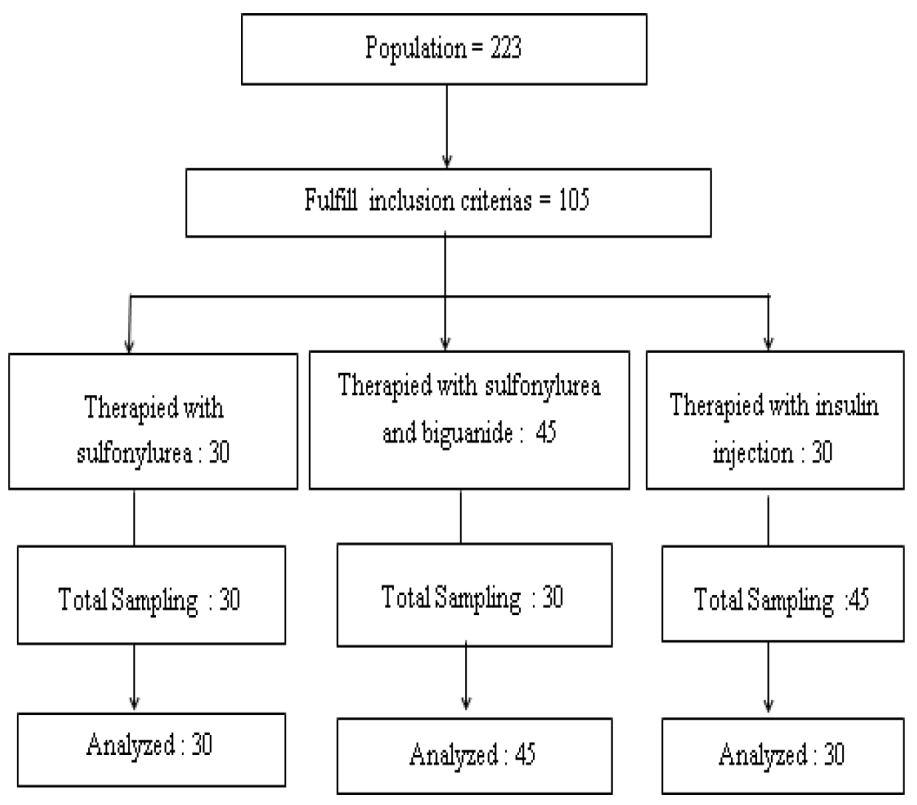

Figure 1: Study flow diagram. 
Table 1: Sample characteristics.

\begin{tabular}{|c|c|c|c|c|}
\hline $\begin{array}{c}\text { Parameter } \\
\text { mean } \pm \text { SD. or amount }(\%)\end{array}$ & $\begin{array}{l}\text { Insulin Group } \\
\qquad(n=30)\end{array}$ & $\begin{array}{l}\text { Sulfonylurea Group } \\
\qquad(n=30)\end{array}$ & $\begin{array}{l}\text { Sulfonylurea-Metformin } \\
\text { Group }(n=45)\end{array}$ & $p$ \\
\hline Age & $51.21 \pm 8.33$ & $57.83 \pm 6.70$ & $55.16 \pm 6.79$ & $0.178^{\mathrm{a}}$ \\
\hline Body Mass Index & $25.83 \pm 4.72$ & $26.54 \pm 5.50$ & $24.51 \pm 4.16$ & $0.255^{\mathrm{a}}$ \\
\hline Gender & & & & $0.235^{\mathrm{b}}$ \\
\hline Male & $8(26.67)$ & $6(20.00)$ & $17(37.78)$ & \\
\hline Female & $22(73.33)$ & $24(80.00)$ & $28(62.22)$ & \\
\hline Education Level & & & & $0.310^{\mathrm{b}}$ \\
\hline Low & $15(50.00)$ & $21(70.00)$ & $23(51.11)$ & \\
\hline Middle & $13(43.33)$ & $6(20.00)$ & $19(42.22)$ & \\
\hline High & $2(6.67)$ & $3(10.00)$ & $3(6.67)$ & \\
\hline Occupation & & & & $0.063^{b}$ \\
\hline Working & $9(30.00)$ & $3(10.00)$ & $15(33.33)$ & \\
\hline Not-working & $21(70.00)$ & $27(90.00)$ & $30(66.67)$ & \\
\hline Diet & & & & $0.044^{\mathrm{b}}$ \\
\hline Yes & $29(96.67)$ & $29(96.67)$ & $37(82.22)$ & \\
\hline no & $1(3.33)$ & $1(3.33)$ & $8(17.78)$ & \\
\hline Exercise & & & & $0.696^{\mathrm{b}}$ \\
\hline Yes & $17(56.67)$ & $15(50.00)$ & $21(46.67)$ & \\
\hline No & $13(43.33)$ & $15(50.00)$ & $24(53.33)$ & \\
\hline Family History of DM & & & & $0.000^{\mathrm{b}}$ \\
\hline Yes & $28(93.33)$ & $10(33.33)$ & $16(35.55)$ & \\
\hline None & $2(6.67)$ & $20(66.67)$ & $29(64.44)$ & \\
\hline \multicolumn{5}{|l|}{ Blood Pressure $(\mathrm{mmHg})$} \\
\hline Systole & $149.89 \pm 25.92$ & $138.40 \pm 27.36$ & $129.81 \pm 16.21$ & $0.011^{\mathrm{a}}$ \\
\hline Diastole & $86.61 \pm 14.33$ & $80.57 \pm 17.49$ & $78.07 \pm 8.59$ & $0.039^{\circ}$ \\
\hline Fasting Plasma Glucose (mg/dL) & $162.44 \pm 61.44$ & $140.42 \pm 58.28$ & $120.89 \pm 60.42$ & $0.391^{\mathrm{a}}$ \\
\hline 2 Hour Post Prandial Plasma Glucose (mg/dL) & $255.54 \pm 101.13$ & $202.27 \pm 77.97$ & $179.38 \pm 87.85$ & $0.964^{\mathrm{a}}$ \\
\hline
\end{tabular}

aanalyzed with one-way anova test, banalyzed with Pearson chi-square test, ${ }^{\mathrm{c}}$ analyzed with Kruskal-Wallis Test

criteria of DM for fasting plasma glucose is $\geq 126 \mathrm{mg} / \mathrm{dL}$ and $2 \mathrm{~h}$ postprandial plasma glucose is $\geq 200 \mathrm{mg} / \mathrm{dL} .{ }^{14}$ Fasting plasma glucose of the sulfonylurea-metformin combination group is within the normal range.

\section{Comparative effectiveness of Insulin, Sulfonylurea and Sulfonylurea-Metformin combination against $\mathrm{HbA} 1 \mathrm{c}$ and eGFR levels}

HbAlc and eGFR are the clinical parameters used to compare the effectiveness of the three treatment groups. Table 3 shows the ratio of HbAlc levels of the patients which are divided into two categories; controlled levels of $\mathrm{HbAlc}(<7 \%)$ and uncontrolled levels $(>7 \%)$. The eGFR values are divided into two categories; normal $(\geq 60$ $\left.\mathrm{mL} / \mathrm{min} / 1.73 \mathrm{~m}^{2}\right)$ and those with impaired renal function $(<60 \mathrm{~mL} /$ $\min / 1.73 \mathrm{~m}^{2}$ ). The analysis was made using non-parametric chi-square tests. As shown in Table 2, HbAlc of patients with the Kruskal-Wallis non-parametric test in the three treatment groups show at least one significant difference exists among the groups $(\mathrm{p}=0.045)$. To find out which groups have significant differences we used Mann-Whitney test for every two groups. The average $\mathrm{HbAlc}$ level of patients in the combination group $(7.46 \pm 1.81)$ is lower $(\mathrm{p}=0.042)$ than in insulin group $(8.27 \pm 1.74)$. According to renal function, there is no significant difference in eGFR in the three groups $(\mathrm{p}=0.476)$ as shown in Table 2.

\section{Association of BMI and family history with $\mathrm{HbA} 1 \mathrm{c}$}

A logistic regression analysis was conducted using the enter method. As shown in Table 3, it was found that subjects with obesity $\left(\mathrm{BMI}>30 \mathrm{~kg} / \mathrm{m}^{2}\right.$ ) has 3.268 times higher probability $(\mathrm{p}=0.001)$ of having $\mathrm{HbAlc}>7$, relative to underweight patients (BMI $<18.5 \mathrm{~kg} / \mathrm{m} 2)$, after adjustment for comorbidity, diet and exercise habit.

\section{DISCUSSION}

The ratio of non-working patients (non-productive) and patients with low education (only graduated from primary school or did not complete primary school) is quite large ( $56.19 \%$ and $75 \%$ respectively). Both characteristics contributed as obstacles in this study. We needed to arrange persuasive discussions with the subjects to tell them that the research would not influence the treatment they would receive (no intervention) and no other consequences such as cost would imply.

The total number of patients who had a history of DM in the family was almost the same as those who did not have, which amounted to $51.43 \%$ of the total patients. However, there may be a bias in these data, because many of the subject patients and their family never visited health care facilities for DM examination since the nature of DM is often asymptomatic. On further interviews with the patients, it was also revealed many of them found out that they had hyperglycemia after a pre-operation 
Table 2: HbA1c and eGFR of the subjects.

\begin{tabular}{ccccc}
\hline $\begin{array}{c}\text { Parameter } \\
\text { (mean } \pm \text { SD) }\end{array}$ & $\begin{array}{c}\text { Insulin } \\
\text { Group }\end{array}$ & $\begin{array}{c}\text { Sulfonylureas } \\
\text { Group }\end{array}$ & $\begin{array}{c}\text { Sulfonylureas- } \\
\text { Metformin } \\
\text { Group }\end{array}$ & $\mathbf{p}$ \\
\hline & & $\mathrm{p}=0.042^{\mathrm{b}}$ & & \\
$\mathrm{HbA1c}(\%)$ & $8.27 \pm 1.74$ & $7.46 \pm 2.25$ & $7.46 \pm 1.81$ & $0.045^{\mathrm{a}}$ \\
$\mathrm{eGFR}(\mathrm{mL} /$ & $85.73 \pm 28.47$ & $86.23 \pm 23.65$ & $78.00 \pm 28.53$ & $0.476^{\mathrm{a}}$ \\
$\left.\min / 1.73 \mathrm{~m}^{2}\right)$ & & & & \\
\hline
\end{tabular}

analyzed with Kruskal-Wallis Test

banalyzed with Mann-Whitney Test

Table 3: Logistic regression analysis with enter method for confounders.

\begin{tabular}{ccc}
\hline Parameter & $\begin{array}{c}\text { Beta } \\
\text { (Standardized } \\
\text { Coefficient) }\end{array}$ & $\mathbf{p}$ \\
\hline BMI $>30 \mathrm{~kg} / \mathrm{m} 2$ & 3.268 & $0.001^{*}$ \\
Family history of DM & 1.616 & $0.002^{*}$ \\
\hline
\end{tabular}

${ }^{*} \mathrm{p}<0.05$, significant; adjusted for comorbidity, diet and exercise.

inspection (in most cases, for cataract surgery), or while hospitalized for other illness. On those occasions, the physician examined their blood glucose levels and if the result showed above normal level, patients were referred to the routine treatment of diabetes.

Interestingly, the average $\mathrm{HbAlc}$ level of patients in the combination group $(7.46 \pm 1.81)$ was significantly lower than in insulin group $(8.27$ $\pm 1.74)$. This finding is consistent with another study which showed that comparable glycemic control could be achieved both in treatments using insulin and gliclazide, a sulfonylurea for newly diagnosed type 2 diabetes subjects. ${ }^{15}$ Insulin in treatments may be considered to be replaced with a combination of sulfonylurea-metformin because the treatment cost with oral antidiabetic is lower compared to insulin. However, further pharmacoeconomics analysis needs to be done to analyze cost-effectiveness between these two medications. On the other hand, invasive insulin injection allows a variety of undesirable effects if the application is not appropriate, such as infections, inflammation or other effects. Since application of oral antidiabetic drugs is easier for patients compared to injection, it probably could improve the patient adherence.

Association of BMI and type 2 DM was found by Michael L. Ganz et al. in $2014 .{ }^{16}$ They conducted a case-control study that analyzed more than 37,000 people and found that people with higher BMI had a stronger risk factor for DM relative to people with lower BMI and type 2 DM risk may be incrementally higher in those with higher BMI. In this study, we found that higher BMI was associated with uncontrolled HbAlc in type 2 DM.

As well known, the pathogenesis of diabetes is based on the fact that the $\beta$-islet cells of the pancreas are impaired, causing a lack of control of blood glucose. In obese individuals, the amount of non-esterified fatty acids, glycerol, hormones, cytokines, proinflammatory markers and other substances that are involved in the development of insulin resistance, are increased. The development of diabetes becomes more inevitable if the failure of $\beta$-islet cells of the pancreas is accompanied by insulin resistance. Weight gain and body mass are central to the formation and rising incidence of type 1 and type 2 diabetes. ${ }^{17}$ This fact makes the weightcontrol program for people with DM more important, besides choosing appropriate therapies. Better weight control management, for instance, with diet or exercise should lead the patients to better control of HbA1c.
In addition, we found that the chance to have HbAlc>7 increased 1.616 times in patients with the history of DM in family compared to the subject who did not have the family history of DM ( $\mathrm{p}=0.002)$. Annis et al., on their survey in 1999 until 2002, found that family history of diabetes was shown to be a significant predictor for the prevalence of diabetes in the adult U.S. population. ${ }^{18}$ The prevalence of diabetes among individuals in this study who had a first-degree relative with diabetes (14.3\%) was significantly higher than that of individuals without a family history of diabetes (3.2\%).

The strength of this study is that we evaluated the efficacy of commonly prescribed antidiabetic drugs on Indonesian patients with type $2 \mathrm{DM}$ and found no differences among the three groups in term of age, gender, BMI, occupation and exercise habit. However, there were several limitations in this study, such as the sample size which was relatively small and no data were available regarding the patient's adherence. Further studies are suggested with a larger number of representative patients of Indonesian population with monitored-compliance which are needed to validate our study result.

\section{CONCLUSION}

In summary, insulin was not more effective compared to sulfonylureas and metformin combination or sulfonylureas monotherapy in decreasing $\mathrm{HbAlc}$ level, but not for eGFR, in age-, sex- and BMI-matched type $2 \mathrm{DM}$ patients in this study site. Patients with family history of DM and obesity have a significant relative risk to get uncontrolled HbAlc.

\section{Standard protocol on approvals, registrations, patient consents and animal protection}

This study has been registered at the Ethics Committee, Faculty of Medicine, Universitas Indonesia-Dr. Cipto Mangunkusumo Hospital (No.76/UN2.F1/ETIK/2015) and the Ethical Committee of Dr. Sitanala Hospital (No. DM.04.05/1/01662/2015). Clinical and habitual information were collected using questionnaires and before taking the blood samples, subjects were kindly asked to read and sign an informed consent.

\section{ACKNOWLEDGEMENT}

This study was supported by Postgraduate Grant, DRPM (Directorate of Research and Community Engagement) Universitas Indonesia.

\section{CONFLICT OF INTEREST}

The authors declare no conflict of interest.

\section{ABBREVIATIONS}

DM: Diabetes Mellitus; eGFR: estimated Glomerular Filtration Rate; HbA1c: Glycated Hemoglobin; BMI: Body Mass Index.

\section{REFERENCES}

1. Wild S. Green A. Global prevalence of diabetes. Diabetes Care. 2004;27(5):1047-53.

2. PERKENI. Konsensus pengendalian dan pencegahan diabetes melitus tipe $2 \mathrm{di}$ Indonesia. Jakarta. Perkeni. 2011.

3. Guariguata L, Whiting DR, Hambleton I, Beagley J, et al. Global estimates of diabetes prevalence for 2013 and projection for 2035. Diabetes Res Clin Pract. 2014;103(2):137-49.

4. Katzung, Bertram G. Basic and clinical pharmacology 9th ed. London: Mc Graw Hill Co; 2004.

5. International Diabetes Federation. Global guideline for type 2 diabetes. IDF. 2012;55.

6. Garber AJ. AACE/ACE comprehensive diabetes management algorithm. Endocr Pract. 2015.

7. Batuman V, Romesh KI. Diabetic nephropathy. Medscape. 2014.

8. Penno G, Solini A, Bonora E, Fondelli C, Orsi E, Zerbini G. HbA1c Variabiity as an independent correlate of nephropaty, but not retinopaty, in patients with type 2 
diabetes. Diabetes Care. 2013

9. Turner RC, Cull CA, Fright V, Holman RR. Glycemic control with diet, sulfonylurea, metformin, or insulin in patients with type 2 diabetes mellitus. Am J Med Assc. 1999;281(21):2005-12.

10. Rao AD, Kuhadiya N, Reynolds K, Fonseca VA. Is the combination of sulfonylurea and metformin associated with an increased risk of cardiovascular disease or all-cause mortality? Diabetes Care. 2008;1672-8.

11. Jeffrey JA, Majundar SR, Simpson SH. Decreased mortality associated with the use of metformin compared with sulfonylurea monotherapy in type 2 diabetes. Diabetes Care. 2002;25(12):2244-8.

12. Hung A, Roumi C, Greevy R, Liu X, Grijala C, Murff H. Comparative effectiveness of incident oral antidiabetic drugs on kidney function. Kidney Intl. 2012;81(7):698-706.

13. Dipiro JT, Well BG. Pharmacotherapy handbook, 7th ed. New York: McGraw Hill Medical; 2009.

14. American Diabetes Association. Standards of medical care in diabetes-2013.
Diabetes Care. 2013;v.36:s11-s66.

15. Chandra ST, Priya G, Khurana ML, Jyotsna VP, Sreenivas V, Dwivedi S, Ammini AC. Comparison of gliclazide with insulin as initial treatment modality in newly diagnosed type 2 diabetes. Diabetes Technol Ther. 2008;10(5):363-8.

16. Ganz ML, Wintfeld N, Li Q, Alas V, Langer J, Hammer M. The Association of Body Mass Index with the Risk of T2DM; a case-control study nested in an electronic health records system in United States. Diabetol Metab Syndr. 2014;6(1):50.

17. Al Goblan AS, Al Alfi MA, Khan MZ. Mechanism linking diabetes mellitus and obesity. Diabetes Metab Syndr Obes. 2014;7:587-91.

18. Annis AM, Caulder MS, Cook ML, Duquette D. Family history, diabetes and other demographic and risk factors among participants of the National Health and Nutrition Examination Survey 1999-2002. Prev Chronic Dis. 2005;2(2).

Article History: Submission Date : 14-04-2018 ; Revised Date : 02-05-2018; Acceptance Date : 27-07-2018.

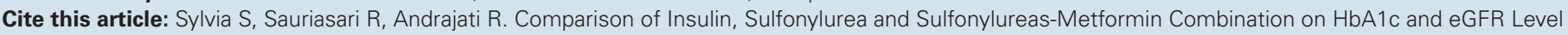
on age-, sex- and BMI-matched Groups on Indonesian Type 2 DM Patients. J Young Pharm. 2018;10(4):471-5. 